\title{
A LEITURA SUBJETIVA NO ENSINO DE LITERATURA: O TEXTO DO LEITOR EM L'ANALPHABÈTE DE AGOTA KRISTOF
}

\author{
LA LECTURE SUBJECTIVE DANS L'ENSEIGNEMENT DE LA \\ LITTERATURE : LE TEXTE DU LECTEUR DANS L'ANALPHABETE D'AGOTA \\ KRISTOF
}

\begin{abstract}
THE SUBJECTIVE READING IN THE TEACHING OF LITERATURE : THE READER'S TEXT IN L'ANALPHABETE OF AGOTA KRISTOF
\end{abstract}

\author{
Rosiane Xypas \\ Grupo de Estudos de Aquisição Francesa da Língua e da Literatura - GEFALL \\ Universidade Federal de Pernambuco- UFPE \\ E-mail: rosiane.xypas@gmail.com
}

\begin{abstract}
RESUMO
No âmbito do ensino da leitura de Obras Literárias completas aos futuros professores de Francês Língua Estrangeira na Universidade, fiz uma pesquisa fundamentada na Teoria da Recepção com a narração autobiográfica L'Analphabète de Agota Kristof (1935-2011). Postulei que para o ensino da leitura literária, uma metodologia centrada no interesse do aprendiz, pudesse facilitar a recepção da Obra. Além disso, me parece ser a temática do Entrelugar muito instigante no tratamento do tema literário. $\mathrm{O}$ objetivo desta pesquisa foi analisar os processos interpretativos dos leitores. Por um lado, investiguei as impressões de leitura da Obra em questão, e por outro lado, verifiquei tanto as condições efetuadas de leitura do texto dos três estudantes quanto o que os fez vibrar na Obra. Pedi para cada um escrever um Diário de leitura. E para mensurar os resultados, criei um Quadro de análise do texto dos leitores. O quadro teórico desta pesquisa se inscreve com Godard (2015) no tocante ao ensino de Literatura de língua francesa; Rouxel e Langlade (2004/2013), para a leitura subjetiva. Por fim, Obras literárias tratando do tema de identidade podem ativar a memória afetiva do leitor ajudando-o na construção de si.
\end{abstract}

Palavras-chave: Leitura subjetiva. Diário de Leitura. Texto do leitor.

\section{RESUME}

Dans le cadre de l'enseignement de la lecture des œuvres littéraires complètes à des professeurs de français langue étrangère (FLE) à l'université, j'ai mené une recherche fondée sur la réception du récit autobiographique L'Analphabète d'Agota Kristof (1935-2011). J'ai postulé que pour l'enseignement de la lecture littéraire une méthodologie centrée sur l'apprenant pourrait faciliter la réception de l'œuvre à lire. Il me semble que la thématique de l'entre-deux ce serait un atout pour les étudiants. L'objectif de cette recherche fut d'analyser les processus interprétatifs des lecteurs. D'une part, investiguer les impressions de lecture de l'œuvre en question, et, d'autre part, vérifier aussi bien les conditions effectuées de lecture du texte des trois étudiants que ce que leur fait vibrer dans l'œuvre. Pour cela, ils ont tenu un journal de lecture. Afin de mesurer les résultats, j'ai créé un cadre d'analyse du texte des lecteurs. Le cadre théorique de la recherche s'inscrit dans le sillage de Godard (2015) en ce qui concerne l'enseignement de la littérature; Et Rouxel et Langlade (2004/2013) pour la 
lecture subjective. Enfin, une œuvre littéraire traitant de la thématique de l'identité peut activer la mémoire affective du lecteur dans la construction de soi.

Mots-clés: Lecture subjective. Journal de lecture. Texte du lecteur.

\begin{abstract}
Within the teaching process of the reading of complete Literary Works to the future professors of French Foreign Language at University, I have made a research based on the Reception Theory with the autobiographical narration L'Analphabète from Agota Kristof (1935-2011). I postulated that for the teaching of the literary reading, a methodology centered on the interest of the apprentice could facilitate the reception of the Work. Besides that, it seems to be the topic of the Between-Place very instigating to the group with which I worked. The aim of this research was to analyze the interpretative processes of the readers. On the one hand, I investigated the impressions of reading of the Work in question, and on the other hand, I verified not only the carried out conditions of reading from the text of the three students but also what made them cheer in the Work. I asked each one to write a reading Journal. To measure the results, I created an analysis framework of the Readers' texts. The theoretical framework of this research inscribes Godard (2015) regarding the teaching of Literature; and Rouxel and Langlade (2004) for subjective reading. Lastly, a literary work addressing the topic of identity may activate the affective memory of the reader helping on the construction of themselves.
\end{abstract}

Keywords: Subjective Reading. Reading Journal. Reader's text.

\title{
INTRODUÇÃO
}

No âmbito do ensino da Literatura em Francês como Língua Estrangeira (FLE), decidi trabalhar com a atividade de leitura literária visando à análise do texto do leitor. Colocar o leitor em foco advém do fomento da motivação da atividade leitora em Literatura na sala de aula do século XXI. O objetivo deste artigo é de compreender os processos subjetivos de na leitura literária de Obras completas com alunos de nível avançado em língua francesa. Para tal, respondo as seguintes perguntas: Como se deram os processos subjetivos deles? Como a atividade de leitura literária preenche os vazios do texto? Como o leitor apreende a obra, sem limitá-la, mas impregnando-a de seus toques peculiares? Quais os estados singulares de realizações textuais autênticas? Como nasce o leitor diferente daquele que era antes de ler a Obra?

A leitura literária é a única atividade respaldo das emoções do leitor literário em ação. Ora, mas quantas dessas emoções não são perdidas, quantos ignorados traços de subjetividade do sujeito leitor também, porque não há, no agir professoral, prioridade no acolhimento do texto do leitor! E, portanto, o investimento da imaginação de sujeitos leitores em atividade poderá ser mensurado através das impressões deixadas em um Diário de leitura, por exemplo, 
criando assim o que chamo de texto do leitor. Para mensurar o texto do leitor, criei um quadro de análise das impressões das leitoras sobre a Obra lida. Meu procedimento metodológico para a análise do texto literário se baseia na Teoria da Recepção notadamente, com a da leitura subjetiva.

Mas por que trabalhar com o texto do leitor? Langlade (2004/2013) vai dizer que o discurso do leitor se inscreve em uma teoria ou em uma moral das reações subjetivas que sentiu no curso da leitura: fascinação, rejeição, tribulação, sedução, hostilidade, desejo etc. $\mathrm{O}$ sujeito leitor investido de fatores psicológicos, de julgamentos morais de sedução ou de repulsão "se lê ou se une à obra" como escreveu Langlade (2013, p. 36). Tomando a leitura subjetiva como metodologia de análise, penso que ela favorece a descoberta do texto singular do leitor literário, além de interrogar bem a noção de texto literário. A teoria da leitura subjetiva em que se baseia Langlade se fundamenta sobre as teorias de Umberto Eco por afirmar que o texto literário apresenta "um caráter incompleto, lacunar”. (2013, p. 33). Já Pierre Bayard apud Langlade (2013, p. 34) “considera a obra literária como, por essência, 'móvel' e que estimam que, cada leitor constrói um texto particular'. Ora, por que não investigar esse 'texto particular?'. Vou mais além. Depois de construir este texto singular, esse sujeito leitor se transforma em quê?

Ora, se existe um texto particular do leitor, existe um geral criado pelo autor. Dito em outras palavras, um texto geral seria aquele que concerne o texto publicado no editor, e o singular, aquele construído pelo leitor. Ainda com Langlade (2013, p. 35) penso que "todo texto singular elaborado por um leitor, quais sejam suas lacunas e suas insuficiências relativas, quais sejam sua parte de delírio, constitui um estado do texto digno de ser apreciado como uma produção de leitura literária" merece atenção no ensino da Literatura. É através desse estado de textos particulares criados pelo leitor que esse artigo quer dar conta.

A leitura subjetiva é tomada aqui como metodologia para análise do texto do leitor. Sendo assim, entendo a atividade leitora como manifestação, explicitação do mundo íntimo do leitor respaldado em seu conhecimento prévio. Ora, se tal atividade é explicitada, ela pode ser analisada. Para tal, escolhi trabalhar com Diários de leitura a fim de verificar os processos subjetivos dos estudantes. Pedi a seis estudantes que lessem a narração autobiográfica L'Analphabète (2004) de Agota Kristof (1935-2011) escritora de origem húngara que decide escrever na língua do Outro na idade adulta. Esta narração autobiográfica conta a história de uma imigrante que chega a um país francófono na idade de vinte e um anos e trata de sua adaptação, combates e embates na língua-cultura do Outro. Embora muito sofrimento e o afirmar da autora que a língua francesa é uma "língua inimiga" (2004, p. 28), ela se torna uma 
das maiores escritoras de expressão francesa de sua época. Trata-se aqui da temática da identidade, da descentração linguístico-cultural e da dimensão intercultural que atravessa todo esse processo. Por isso, os estudantes escolhidos para esta pesquisa foram de nível avançado, porque supus terem eles certa intimidade com a língua francesa a ponto de lhes aflorar a metalinguagem desencadeada pela atividade de leitura literária demandada.

Postulo que a situação de bilinguismo da autora poderá levar os estudantes a questionar seu próprio bilinguismo. Esse encontro com as situações vividas pelo personagem pode levar os estudantes a uma reflexão metalinguística de seu aprendizado na língua francesa. Como queria Proust apud Compagnon (2001, p. 144), "pensar cada vez mais em uma visão privativa da leitura", indicando que o objeto literário é ponte segura na representação de um texto que instrui e de um leitor que constrói. É essa construção que me interessa nesse momento. Ela poderá favorecer a criação de um leitor diferente depois do contato com a Obra?

Este artigo está divido em três partes: na primeira, apresentaremos a abordagem teórica, na segunda, a análise dos dados, e na terceira, as considerações finais.

\section{ABORDAGEM TEÓRICA: A LEITURA SUBJETIVA NA ATIVIDADE DE LEITURA LITERÁRIA}

O ensino da literatura em Francês Língua estrangeira se preocupa com o sujeito leitor no tocante às atividades de leitura em voz alta e a leitura silenciosa. Fundamenta-se a exploração pedagógica de atividades de leitura no que concerne igualmente a compreensão global do texto, a compreensão detalhada e atividades de pós-leitura. Ela tenta englobar o sujeito leitor por completo, ou seja, em cada parte de sua construção de sentidos.

Michel Pendanx apud Cuq e Gruca (2005), propõe atividades matrizes nas quais se podem cruzar, contornar, viabilizar, descobrir, entre outras a fim de adaptá-las ao nível da sala de aula com marcas particulares de suportes com a funções voltadas às tarefas:

1. A função de "descoberta-exploração" com o intuito de sensibilizar o leitor a um problema ou a um ponto de língua desconhecido.

2. A função de "estruturação" que engloba igualmente a conceitualização.

3. A função de "treino" que apela para a memorização e a autonomização.

4. A função de "avaliação" que favorece a autoavaliação. (2005, p. 446).

Destas funções, optamos pela quarta para refletir neste artigo, porque pensei eu, em implicar os estudantes na tarefa da metalinguagem. Ora, segundo Godard (2015) quanto ao ensino da Literatura em FLE, tem-se que se levar em conta os altos e baixos da 
presença/ausência da Literatura no ensino do FLE. A Abordagem comunicativa dos anos 70 a traz de volta, mas com uma aplicação dubitativa no sentido de priorizar sua função social voltada apenas ao aprendizado da língua-cultura, mas mais a língua, de fato, ou seja, mais os aspectos gramaticais que a cultura, ou seja, os aspectos peculiares de todo texto literário. Em 2001, com a Perspectiva acional, o ator social, quer, dizer, o aluno se vê novamente com o texto literário nos livros didáticos, mas se continua a explorar o texto em questão como mero texto comunicativo. Ora, este não é um mero texto comunicativo. A propósito, o que ele comunica? Enfim, suas características, que serão apresentadas mais adiante ficam pouco ou quase nada exploradas com esse método de análise. E onde está e como fica o sujeito leitor?

Entretanto, com a leitura subjetiva se preocupando com a exploração pedagógica dos textos literários, tem-se, por exemplo, a exploração gramatical priorizada com tarefas que relevam certo do campo lexical, mas visando à explicitação dos sentidos do leitor. Existem atividades de leitura que se volta para o dizer, o fazer e o sentir dos personagens, mas sempre dentre essas tarefas, a de implicar o leitor literário com perguntas do tipo: que você pensa? O que você sentiu ao ler tal passagem? Se fosse você como pensa que agiria? ${ }^{1}$ Entretanto, atividades desse tipo ficam limitadas apenas aos primeiros textos do livro didático em questão. Pode-se pensar em uma exploração pedagógica do texto literário fundamentada na leitura subjetiva, como veremos a seguir.

Antes de apresentar a teoria da leitura subjetiva e ensino de Literatura que sustenta nossa análise, palavras como texto literário; leitor literário e leitura literária serão brevemente apresentadas neste artigo.

O texto literário é aquele que apresenta diversas características tais como, metáforas, uma linguagem singular e múltipla e é também um espaço psicossocial no qual apenas a atividade de leitura poderá acioná-lo para que o leitor "viaje" para além de si mesmo como também permita o processo de uma viagem de retorno a si. Mais uma característica digna de nota, ele é polissêmico. Graças a esta característica, ele se alimenta de um eterno presente permitindo injunções e ajustamentos, cooperações e complementos viabilizados por um sujeito leitor que o move. As funções do texto literário são igualmente diversas tanto no âmbito social quanto no âmbito da esfera íntima do ser. Mas essa vida em movimento acordada ao texto literário advém graças, por um lado, ao autor, e por outro, ao leitor. Como diz Jouve (2012, p. 62), "Daí deduzir que o texto não tem sentido próprio e que os conteúdos

\footnotetext{
${ }^{11}$ Ver a este propósito o livro didático, notadamente os sete primeiros textos, La Francophonie progressive de la Francophonie de Nicole Blondeau e Ferroudja Allouache. Paris: CLE - International, 2008.
} 
que acreditamos nele desvelas são puras construções do leitor". É deste último e de todas suas impressões desprendidas na leitura que desejo tratar agora.

Quanto ao leitor literário, ele é um sujeito social que faz parte da sociedade escolar e universitária. Ele é real e o busco no âmbito sócio-institucional para lhe compreender, sem o reduzir em sua ação. Mas o que busco de fato entender é o leitor em suas três fases 'sagradas': antes, durante e depois da leitura. O leitor em sua completude de prazer leitora. Pois este leitor, como diz Jouve (2012, p. 61) renova "o prazer da interpretação em cada leitura". Assim, em busca de definir o leitor literário, me vem à mente o prefixo latino alter. No dicionário alter significa 'um outro, outrem, diferente, oposto'. Aqui proponho, entretanto que alter suscite o leitor com o seu outro-diferente, modificado, modulado, diverso. Vou mais além, proponho a junção do prefixo alter + leitor doravante alterleitor que defino como leitor real porque perto de si mesmo desafiando-se entre limites e fronteiras, descobrindo-se entre sensações e desafios.

Esse alterleitor pode favorecer a uma associação de ideias que tenho sobre a atividade de leitura literária segundo a qual possa ter a intenção de fazer do $e u$ um outro diferente.

Amparando-me na ideia que a leitura literária cria expectativas, que pode provocar estranhamentos no leitor pelas associações feitas de diferentes maneiras como aliando-se à comparação com o vivido, penso em tarefas que viabilizem a explicitação das impressões do leitor visando a estimulá-lo em sua formação. Em resumo: a leitura se torna assim como um despertar de constelações nas quais o horizonte de expectativas se amplia forte e gradualmente dando a sensação a esse leitor literário aqui tratado, que ele é um alterleitor que se descobre Outro-diverso. Finalmente, busco compreender como o leitor sente o texto que lê, por isso, adoto uma abordagem pragmática que releva daquela que se interessa pelo leitor. Mas, por que se preocupar com o leitor na era da distração? Compagnon (1998/2001, p. 139) já dizia desde o século passado que "o elemento literário a ser examinado com maior urgência é o leitor”. (Em itálico no texto). E “[...] a leitura tem a ver com empatia, projeção, identificação". (op. cit, p. 143).

Com efeito, nesta análise priorizo a relação do leitor com a Obra. Mas isso ainda não é suficiente. Precisa-se, pois, da atividade de leitura literária para que se desencadeie a alavanca que falta para a construção do alterleitor. Parece-me oportuno representar com uma figura, meu esquema mental sobre a tríade composta por leitor-Obra-leitura a fim de se compreender os passos propostos na construção do alterleitor conceito criado e defendido por mim. Observe a pirâmide abaixo: Ela apresenta em sua base as palavras Obra e Leitura e no topo, Leitor. 


\section{Leitor \\ Obra $\Longleftrightarrow$ Leitura}

Figura 1 - fonte da autora

Esses três elementos que formam a figura acima é como represento esta tríade. Eu os considero como um alter, a saber, amigos inseparáveis, por isso fundamentam a construção do alterleitor, evocado assim em um gráfico abaixo:

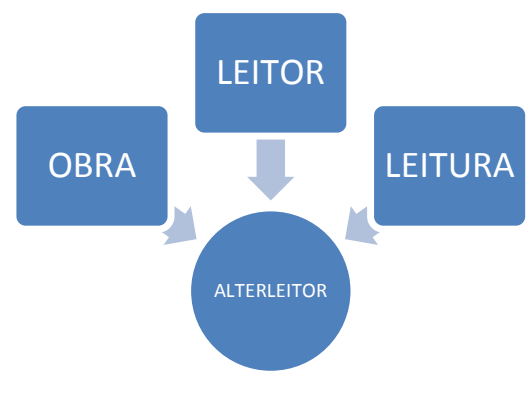

Figura 2-Fonte da autora

$\mathrm{O}$ alterleitor é um ser em elaboração, em processo. Eu o representei em uma figura localizada em um centro num círculo que simbolicamente suscita continuidade. Ressalto o valor que dou aos três elementos ao redor dele indicando que ele só pode ser constituído a partir desta tríade - leitor-Obra-leitura - dinâmica que busco compreender nos processos do investimento do imaginário daquele que virá se tornar um alterleitor. Assim como estamos falando em processo, me parece ter ficado claro que partimos para ler uma Obra como leitor e só depois da atividade de leitura é que nos tornamos um alterleitor, leitor diferente e um Outro de si mesmo.

Mas, para acompanhá-lo nesta transformação, preciso se faz colher seus textos de leitor. Penso que as acolhidas das impressões de leitura do leitor literário podem ser feitas em suportes como o diário virtual, ou seja, o blog, o Twitter, o facebook igualmente, ou todo outro suporte no qual os sentimentos do $E u$ possam ser explicitados. Mas nesta pesquisa pedi aos estudantes que escrevessem seus diários de leitura em um caderno. Demougin afirma que

“os escritos reativos e o diário de bordo contribuíram enormemente a apreender o que o leitor escolar de literatura, até em seus silêncios, e anotações marginais em seus romances, investe em leitura, compilações integrando marcas do leitor são ferramentas preciosas para adentrar nos caminhos íntimos do leitor de literatura.” (DEMOUGIN, 2004a, p. 118). 
Pensando ainda na leitura subjetiva como método de análise, desde 2004 na França e no Canadá se trabalha com a leitura subjetiva na sala de aula. ${ }^{2}$ No momento atual no Brasil ${ }^{3}$, penso que propor a leitura subjetiva e o conhecimento destas teorias aplicáveis ao ensino da Literatura na sala de aula é algo possível. Preciso ficar claro que a leitura subjetiva não consiste apenas em verificar a implicação do leitor na Obra que é atualizada pela ancoragem da leitura no imaginário daquele que lê apresentando estados singulares de realizações textuais autênticas. A leitura subjetiva destaca "a parte do íntimo do sujeito na leitura do texto" segundo Louichon (2004b, p. 49) e além disso, "participa assim da afirmação da pessoa, da construção de seu projeto próprio, frequentemente mesmo contra o autor do texto lido" como escreveu Massol (2004c, p. 32). Assim, o diário de leitura pode destacar os termos ligados às impressões da leitura do leitor singular modificador de Obras. Estes termos podem apresentar um vocabulário ou campos léxicos que relevam da dimensão afetiva da língua que representa diversos sentimentos do leitor acionados graças à atividade leitora.

Neste artigo, a análise do texto do leitor é apreciada como uma produção de leitura visando às atividades de complemento dos vazios do texto. Procuro apreender como o leitor habitou a Obra. No tocante ao gênero aqui trabalhado, duas razões me fizeram privilegiar a narrativa: a primeira, é que ela "ocupa para o sujeito uma função estruturante. (...) Autoriza-o a constituir sua identidade dominando relativamente, a parte do imaginário e do simbólico, a idealização e a identificação", segundo Freud apud Piégay-Gros (2004d, p.75-76). A segunda razão é que conforme Reuter (2009, p. 34-35) "não é necessário de modo algum subestimar que o personagem seja um dos suportes essenciais, de ordem sociocultural e de ordem afetiva do investimento, ideológico e psicológico, dos autores e leitores".

Ora, no contexto da leitura da narração autobiográfica escolhida neste estudo, como os estudantes se apropriaram do texto? Para responder a esta questão, vou verificar os processos subjetivos desses graças à escrita em seus diários de leitura como já falamos acima. Os termos que os leitores associam à leitura da narração são frequentemente ligados ao vocabulário amoroso, afirma Langlade (2013). Vamos então verificar. Quando eles escrevem com toda a liberdade de expressão possível em seus diários de leitura literária, eles destacam suas impressões do texto que podem servir de "afirmação da pessoa e [colaboram] com a construção de si” como afirma Massol (2004c, p.32). O romance encarado desta maneira é igualmente representado como "um lugar para o sujeito habitar suas palavras de desejo"

\footnotetext{
${ }^{2}$ Ver Rouxel, A. e Langlade, G. Le sujet lecteur - Lecture subjective et enseignement de la littérature, Rennes - PUR, 2004 ; Gervais, B. e Bouvet, R. Théories et pratiques de la lecture littéraire. Quebec, PUQ, 2007. No Brasil, Neide Luzia de Rezende et al traduziram alguns artigos do livro de Rouxel e Langlade (2004).

${ }^{3}$ No Scielo encontrei 6 ocorrências das áreas de humanas que trazem as palavras leitura subjetiva.
} 
(2004c, p.76). O romance favorece de fato uma leitura de adesão que "abala a emotividade inteira e produz uma verdadeira captação sobre o leitor" (2004c.p.74). Esta captação é o que faz vibrar o leitor na leitura do texto literário.

O que faz vibrar o leitor na leitura literária deveria, pois ter um lugar de análise no ensino da Literatura facilitando um processo pedagógico, supostamente colocado em destaque, chamado o estranhamento do leitor literário. A leitura literária de certo "encantamento [visto como] uma energia em duplo sentido desloca simultaneamente o leitor dele mesmo e o destaca a força do estranhamento do texto" como afirma Roger (2004e) apud Rouxel e Langlade (2013, p. 52). Neste deslocamento se encontra em processo um novo leitor, um leitor outro diferente, o alterleitor. É nesse sentido que vai meu conceito de leitura literária quer dizer, como diz Roger (2004e) “devastar os textos para reinventá-los”. (Op. cit, p. 52). É apenas no reinventar que a vida é possível, que nos tornamos outro, que a leitura se torna singular para ampliar os horizontes do leitor.

Enfim, a ideia da construção do alterleitor, vejo ações claras: quando leio um livro posso emprestá-lo minhas infinitas vozes porque o livro, por mim, deve ser alterado, esmiunçado em todas as partes: é quando eu, enquanto sujeito leitor, me instalo em um lugar que posso chamar de meu. Piégay-Gros (2004d), diz que, de fato, ler romances é aprender a amar, a desenhar, a se comportar de maneira diferente-sublime, poética, ideal deixando o terreno plano do quotidiano e a perda doce do prosaísmo.

Próxima à escrita do investimento subjetivo da atividade de leitura dos estudantes, há no mínimo uma dupla problemática:

a) O que relevar do material recolhido dos diários de leitura deles?

b) Como interpretá-los?

Assim, a análise do texto do leitor será pensada, refletida como uma produção de leitura como dissemos acima. Ela priorizará as atividades de complemento dos vazios do texto, mas também a apreensão de como o leitor habitou a Obra. Será que poderei compreender a implicação do leitor na atualização da Obra e sua ancoragem da leitura no imaginário daquele que lê? É no exercício do acolhimento de seus estados singulares de realizações textuais autênticos que enfim uma atividade de leitura literária deve ser aplicada na contemporaneidade dos estudos literários.

Justifico a escolha desta metodologia de estudo como segue: quando o leitor lê obras literárias, ele se abre a um mundo que ele não construiu e reage a cada linha, parágrafo, capítulos lidos. Em contrapartida, em uma leitura de experts, existe a leitura subjetiva. Mas, qual o interesse deste tipo de leitura? 1. Desvendar o universo particular do leitor; e 2. Fazer 
emergir seus traços subjetivos de leitura. Para analisar este universo particular e fazer emergir os traços de subjetividade na leitura literária, minha análise se volta para a observação dos termos que fazem ecos e sentidos imbrincados nas reações do sujeito-leitor e aquilo que dele o resulta.

Segundo Langlade (2013, p. 32) «a vida útil de um texto se fundamenta sobre os martelamentos com as lembranças, as imagens mentais, as representações íntimas de si, dos

Outros, do mundo do leitor." É também “pensar em lembranças circulares desencadeadas pelas leituras" (2013, p. 32). As lembranças circulares me parecem uma bela imagem para pensar nas ativações da memória referentes às situações vividas pelos personagens porque é através delas que os leitores poderão investir seus imaginários, construindo-se alterleitor.

Portanto, o personagem visto como um meio de investimento do imaginário do sujeito leitor merece toda minha atenção. Postulo que o que está em jogo nesse processo da leitura subjetiva, é a identificação do sujeito leitor às situações vividas pelos personagens na ficção. Langlade (2013, p.26) se interroga afirmando "que existe na atividade leitora uma presença insistente às vezes a irrupção de ecos subjetivos que fazem cortejo à leitura de uma obra literária." O que fazer com essa irrupção advinda da atividade leitora? Pois, "longe de serem escórias da atividade leitora não seriam estes indícios de uma aproximação do texto, de uma singularidade da obra pelo leitor?" (2013, p. 27). Entendo que a irrupção da subjetividade na atividade leitora deve ser levada em conta através das marcas de subjetividade que constituem as reações que surgem à consciência do leitor durante a leitura.

O leitor subjetivo que é aquele que faz emergir suas leituras matrizes, arcaicas, de infância que são ativadas durante a leitura que, portanto, se faz em privado. Langlade (2013) afirma que "essa leitura com fortes investimentos afetivos... [revelam] suas obras a si e [explicitam] o vocabulário amoroso que dela se desprende”. (Op.cit. p, 30). Enquanto o leitor arcaico pratica uma leitura mais íntima, o leitor expert pratica uma leitura conceitual. Esse adota uma distância crítica, mas esta postura não deve se caracterizar como a única possível no modo de ler porque podem as reações subjetivas agir como filtro catalizadores de leitura que alimentam o percurso interpretativo indo até a dimensão afetiva do leitor, diz Langlade (2013). Eu acrescento as afirmações de Langlade que esse processo favorece a construção de sentidos sem dúvida, mas também a construção do alterleitor.

\section{A LEITURA SUBJETIVA COMO METODOLOGIA DE ANÁLISE DOS DIÁRIOS DE LEITURA}


Em busca de um método de análise das impressões colhidas no Diário de leitura dos estudantes apropriamo-nos dos postulados de Langlade (2013) no tocante à leitura subjetiva enquanto uma produção de atividade leitora e complemento dos vazios do texto. $\mathrm{O}$ complemento desses vazios do texto me permitirá analisar o que foi destacado pelo sujeito leitor, sua apropriação do texto, sua singularização da obra lida.

A fim de tornar minha análise mais prática criamos um quadro para avaliar a singularidade do texto do leitor, quer dizer, para desvendar o universo particular do leitor e de fazer emergir seus traços de subjetividade de leitura.

Com o quadro, espero mostrar de forma didática e clara e verificar a presença de um vocabulário rico da conotação do vocabulário amoroso; as lembranças circulares desencadeadas pela leitura da narração; à identificação do leitor que faz eco e como resultado a atualização da obra favorecendo a ancoragem da leitura no imaginário de quem lê e os estados singulares de realizações textuais autênticos. Vamos às análises.

Análise da produção das leitoras Léa, Jade e Marie ${ }^{4}$.

Quadro 1- Fonte da autora: Sobre o texto

\begin{tabular}{|c|c|c|}
\hline Sobre o texto Léa & Sobre o texto Clhoé & Sobre o texto Marie \\
\hline $\begin{array}{l}\text { A autora utiliza frases curtas, eu } \\
\text { me sinto livre para imaginar os } \\
\text { detalhes. Imagino os espaços, as } \\
\text { personagens e os sentimentos. }\end{array}$ & $\begin{array}{l}\text { O texto é composto de várias frases } \\
\text { curtas, simples e diretas. }\end{array}$ & $\begin{array}{l}\text { A narração pode ser ensinada aos } \\
\text { alunos de nível iniciante, } \\
\text { intermediário e avançado. }\end{array}$ \\
\hline
\end{tabular}

No Quadro1, leio que as três estudantes estão cientes sobre a forma do texto, e apresentam suas impressões do lido: uma descreve que o texto é composto de várias frases curtas, simples e diretas o que me faz entender que ele é fácil de se compreender; a outra diz mesmo que a Obra pode ser utilizada na sala de aula nos três níveis de aprendizado preconizado pelo Quadro Europeu Comum de Referência para as Línguas (QECRL, 2001). Enquanto duas dentre as três mencionam a questão formal, necessária no agir professoral, uma delas apenas diz que como a autora utiliza frases curtas, ela se sente livre para imaginar os detalhes, os espaços, as personagens e os sentimentos. Não seria esta o valor a ser acordado pelo leitor na leitura de Obras fáceis a fim de que ele possa desenvolver seu imaginário? Além disso, temos aqui manifestas as impressões da leitura preenchendo os vazios do texto.

Análise da produção das leitoras Léa, Jade e Marie.

Quadro 2- Fonte da autora: Estados singulares de realizações textuais por um vocabulário amoroso

\footnotetext{
${ }^{4}$ Todos os nomes são fictícios.
} 


\begin{tabular}{|l|l|ll|}
\hline \multicolumn{2}{|c|}{ O texto de Léa } & \multicolumn{1}{|c|}{ O texto de Jade } & \multicolumn{2}{c|}{ O texto de Marie } \\
\hline O prazer de entrar e visitar outras & Adorei o estilo do autor, muito & L'Analphabète é um retrato \\
realidades, outros mundos através & direto e cheio de imagens simples, & tocante... o livro é emocionante, \\
dos livros? & com uma força que parece & (...) importante... \\
E eis que eu já estava & sustentado pela língua francesa, & \\
completamente apaixonada e não & diretamente de sua alma eslava. & \\
podia mais deixar o livro! & & \\
A emoção a 100\% quando terminei & & & \\
o romance. & & & \\
\hline
\end{tabular}

Os estados singulares de realizações textuais se manifestam através do vocabulário amoroso mencionado por Langlade. A leitora Marie se refere ao livro qualificando-o de 'emocionante', importante e tocante'. Já Jade se refere na verdade ao 'estilo do autor'. Mas é Léa sem sombra de dúvidas que apresenta com palavras fortes como 'prazer'; 'completamente apaixonada'; 'a emoção a 100\%' que explicita o que lhe faz virbar na Obra dando ênfase no vocabulário amoroso.

Análise da produção das leitoras Léa, Jade e Marie.

Quadro 3- Fonte da autora: Evocação de outras leituras literárias/da vida/ do mundo

\begin{tabular}{|c|c|c|}
\hline O texto de Léa & O texto de Clhoé & O texto de Marie \\
\hline $\begin{array}{l}\text { Constatei uma semelhança que a } \\
\text { autora tem com outro escritor que } \\
\text { gosto muito... Marcel Pagnol no } \\
\text { tocante ao aprendizado da leitura } \\
\text { quando criança. }\end{array}$ & $\begin{array}{l}\text { Se eu observei esta experiência nos } \\
\text { outros, eu vivi algumas coisas } \\
\text { diferentes... } \\
\text { Vi outras pessoas viverem o drama } \\
\text { de Agota em relação ao francês, } \\
\text { porque tinha muito estrangeiro na } \\
\text { Argélia que estudavam na Escola } \\
\text { de Ensino Médio que eu } \\
\text { frequentava também. Os alunos se } \\
\text { exprimiam em francês, mas a } \\
\text { língua francesa lhes era estrangeira } \\
\text { tanto no tocante aos sotaques deles, } \\
\text { quanto pela formacão das frases. }\end{array}$ & $\begin{array}{l}\text { Não é fácil se adaptar totalmente } \\
\text { em uma nova cultura, sobretudo } \\
\text { quando não se sente acolhida. É } \\
\text { uma prisão sem muros: a família, } \\
\text { os amigos, o país natal, tudo é } \\
\text { saudade... }\end{array}$ \\
\hline
\end{tabular}

Uma característica do texto literário é que ele evoque momentos da vida e ou da representação do mundo do leitor como também histórias lidas em outros textos literários convocando o conhecimento prévio do leitor, concebido pela visão da vida e do mundo. Constato com as palavras encontradas nos Diários de leitura das estudantes, que Marie se lê 
na obra no tocante ao sentimento de acolhida do país estrangeiro. A estudante Clhoé evoca passagens de sua vida quando se encontrava na Argélia e Léa demonstra que uma passagem especial da Obra estudada lhe remeteu ao autor Marcel Pagnol no tocante à aprendizagem da leitura como autodidata na infância.

Análise da produção das leitoras Léa, Jade e Marie.

Quadro 4 - Fonte da autora: A identificação do sujeito leitor com as situações vividas pelo personagemnarrador.

\begin{tabular}{|c|c|c|}
\hline O texto de Léa & O texto de Clhoé & O texto de Marie \\
\hline $\begin{array}{l}\text { Tive uma enorme identificação: ela } \\
\text { adora ler! Eu me disse: "eu } \\
\text { também" ! } \\
\text { A empatia fortemente presente, } \\
\text { desejo que esta etapa de sofrimento } \\
\text { para e que ela possa sair desse } \\
\text { porque sinto sua solidão e sua dor. } \\
\text { (...) Se sentir desenraizado deve ser } \\
\text { bem horripilante. Admiro a força } \\
\text { dela e a resiliência quando se } \\
\text { concentra na escrita. } \\
\text { (...) Eu percebo o quanto esta } \\
\text { experiência foi difícil e o quanto a } \\
\text { literatura a ajudou a superar tudo } \\
\text { isso. }\end{array}$ & $\begin{array}{l}\text { Minha identificação com a } \\
\text { experiência do autor é indireta. Ao } \\
\text { contrário de Agota (...) foi-me } \\
\text { necessário e me é até agora um } \\
\text { exercício de adaptação ao } \\
\text { português, que parece um pouco ao } \\
\text { exercício que faz Agota para } \\
\text { escrever em francês em uma } \\
\text { proporção diferente porque a } \\
\text { língua me é familiar. Eu me } \\
\text { reconheci na narração de Agota, } \\
\text { sobretudo quando ela fala, na } \\
\text { página } 42 \text { do deserto social e } \\
\text { cultural vivido. Mesmo que eu } \\
\text { tenha me integrado na escola } \\
\text { depois de um momento, as } \\
\text { referencias culturais eram } \\
\text { suficientemente confusas para } \\
\text { levar esta sensação de deserto, } \\
\text { porque eu não era nem Argelina } \\
\text { nem Francesa e as referências do } \\
\text { Brasil não eram facilmente } \\
\text { acessíveis. }\end{array}$ & $\begin{array}{l}\text { Vivendo em um país com um } \\
\text { grande número de imigrantes, pude } \\
\text { me identificar com o autor e suas } \\
\text { situações descritas no livro. } \\
\text { Mesmo que eu viva em uma época } \\
\text { diferente e que eu já soubesse falar } \\
\text { a língua do país onde morava. Há } \\
\text { um desejo de representações que } \\
\text { não temos e às vezes somos } \\
\text { obrigados de ser alguém que não } \\
\text { somos: gestos, a entonação, o } \\
\text { modo de ser e de pensar. E tudo } \\
\text { isso, mesmo quando partimos } \\
\text { voluntariamente! }\end{array}$ \\
\hline
\end{tabular}

Antoine Compagnon (2001, p. 144) fala da importância da identificação provocada pelas situações vividas pelos personagens na construção do sujeito leitor. Quanto à 
identificação, Marie fala da difícil adaptação exigida pelos nativos mencionando ser obrigada a ser alguém que não é, por exemplo, tendo que adotar gestos e modos de pensar do Outro. Jade, por sua vez, fala sobre a identificação no que concerne ao sentimento de deserto social e cultural vivido. Todavia, Léa diz que sua forte identificação foi com o gostar de ler, mas também como o sofrimento dado ao desenraizar-se da terra natal, tocada pela leitura ela a qualifica de horripilante!

Análise da produção das leitoras Léa, Jade e Marie.

Quadro 5- Fonte da autora: Representação de si

\begin{tabular}{|c|c|c|}
\hline Léa & Clhoé & Marie \\
\hline $\begin{array}{l}\text { Quantas vezes não me evadi... } \\
\text { Terminei, pois minha leitura com } \\
\text { lágrimas nos olhos e com um } \\
\text { desejo de devorar seus ouros } \\
\text { romances! }\end{array}$ & $\begin{array}{l}\text { (...) de volta da Argélia, me } \\
\text { encontrei face às minhas limitações } \\
\text { em relação à língua portuguesa. } \\
\text { Sinto, entretanto dizer como Agota } \\
\text { "sei que nunca escreverei o } \\
\text { português como escrevem os } \\
\text { escritores brasileiros (...), mas eu o } \\
\text { escreverei como posso, o melhor } \\
\text { que posso". Esta frase se aplica } \\
\text { também ao francês para mim, } \\
\text { porque eu o aprendi mais tarde, aos } \\
\text { cinco anos e meio. }\end{array}$ & $\begin{array}{l}\text { É necessário escolher entre uma } \\
\text { vida solidária e uma vida horrível } \\
\text { em um país devastado pela guerra? } \\
\text { (...) o choque cultural pode ser tão } \\
\text { forte que muitos imigrantes não } \\
\text { chegam a se adaptar e entrar no } \\
\text { país deles. }\end{array}$ \\
\hline
\end{tabular}

É importante ressaltar o ponto central que releva da construção de si enquanto ser social. Marie fala do choque cultural e da adaptação e escolha a fazer da terra do Outro. Me parece doloroso este processo para ela mesma, pois revela essa consciência sobre as dificuldades da descentração. Jade fala, por sua vez, que de volta da Argélia teve que encarar seus próprios limites, não em relação à língua francesa, mas a portuguesa! Quanto à Léa, a representação de si é cheia de emoção e conclui que terminou à leitura com lágrimas nos olhos com desejo de 'devorar outros livros da autora estudada!'

\section{CONSIDERAÇÕES FINAIS}

$\mathrm{Na}$ introdução deste artigo, escrevi que pensar cada vez mais em uma visão privativa da leitura indica o objeto literário como ponte segura na representação de um texto que instrui 
e de um leitor que constrói. E fiz a seguinte pergunta: Essa construção poderá favorecer a criação de um leitor diferente depois do contato com a Obra?

Para mim, uma das funções da leitura literária é de fazer mover o sujeito leitor para tocá-lo ao sabor do prazer da leitura. Construí-lo como um leitor outro diferente daquele que era antes de começar a ler a Obra. Esse alterleitor é, pois, digno de notas, motor da atividade leitora na Literatura.

Quanto às estudantes, não só apenas constatei que todas três apresentaram em seus Diários de leitura, um campo lexical pautado em palavras de cunho do vocabulário amoroso, como também da emoção e do prazer: "prazer de entrar”; “já estava completamente apaixonada"; "adorei o estilo do autor"; "a obra tocante, emocionante, importante"; Quanto às lembranças circulares, admito à evocação às outras leituras literárias, à vida e ao mundo: "a semelhança da autora com o outro, Marcel Pagnol"; "vi outras pessoas viverem o drama de Agota em relação ao francês"; "Não é fácil se adaptar a uma nova vida... é uma prisão sem muros"; Quanto à identificação ela se mostra assim: "tive uma enorme identificação..."; "Eu me reconheci na história de Agota sobre o deserto social e cultural vivido"; "me identifiquei com a autora e suas situações descritas no livro"; Quanto às representações de si, todas três têm suas histórias de vida e se apropriam diferentemente da Obra segundo o valor acordado à mesma.

Para concluir, a análise do texto do leitor discorrida neste artigo, teve como objetivo compreender os processos subjetivos do sujeito leitor na atividade de leitura. Ficou claro para mim que houve mudança do estado singular do leitor literário depois de ler a obra escolhida e a construção da alteridade como sujeito leitor pode ser percebida por todas as impressões explicitadas. A atividade leitora preenche os vazios deixados pelo texto todas as vezes que o sujeito leitor investe seu imaginário nele impregnando a obra lida com seus toques particulares. Enfim, os estados singulares de realizações textuais autênticas advêm na tomada de consciência do leitor desde que o agir professoral o proporcione. Quer dizer, desde que se pense em atividades leitoras que impliquem o sujeito leitor na mesma e logo não se limitem aos aspectos formais do texto, como por exemplo, perguntas que visem apenas saber o que fez, o que diz e o que sente tal e tal personagem.

Enfim, o professor pode abrir um espaço de leitura atenta à construção não mais apenas de sentido, mas de um NASCER DE UM OUTRO LEITOR, UM ALTERLEITOR.

\section{REFERÊNCIAS}


COMPAGNON, Antoine. (Trad. Cleonice Mourão e Consuelo Santiago). O Demônio da Teoria - Literatura e senso comum. Minas Gerais: Humanitas, 2001.

CUQ, Jean-Pierre e GRUCA, Isabelle. Cours de didactique du français langue étrangère et seconde. Grenoble : PUG, 2005.

DEMOUGIN, Patrick. Le lecteur et sa parole : traces écrites d'une parole recomposée dans l'acte de lecture. In - ROUXEL, A. et LANGLADE, G. Le sujet lecteur -Lecture subjective et enseignement de la littérature. Rennes: PUR, 2004a.

GODARD, Anne (Sous la dir.). La littérature dans l'enseignement du FLE. Paris: DIDIER, 2015.

JOUVE, Vincent. Por que estudar Literatura ? (Trad. Marcos Bagno e Marcos Marciolino). São Paulo: Parábola, 2012.

La lecture comme retour sur soi: de l'intérêt pédagogique des lectures subjectives. In

- ROUXEL, A.; LANGLADE, G. e REZENDE, Neide Luzia de. Leitura subjetiva e ensino de literatura. São Paulo : Alameda, 2013.

KRISTOF, Agota. L’Analphabète. Paris: ZOE, 2004.

LANGLADE, Gérard. O sujeito leitor, autor da singularidade da obra In - ROUXEL, A.; LANGLADE, G. e REZENDE, Neide Luzia de. Leitura subjetiva e ensino de literatura. São Paulo : Alameda, 2013a.

LOUICHON, Brigitte. Gide lecteur d'Armance ou la complexité du sujet lecteur. In ROUXEL, A. et LANGLADE, G. Le sujet lecteur -Lecture subjective et enseignement de la littérature. Rennes: PUR, 2004b.

MASSOL, Jean-François. Les subjectivités d'un romancier objectif : à propos de R. martin du Gard - In - ROUXEL, A. et LANGLADE, G. Le sujet lecteur -Lecture subjective et enseignement de la littérature. Rennes: PUR, 2004c.

PIEGAY-GROS, Nathalie. La lecture romanesque, de la frustration à l'assouvissement. In ROUXEL, A. et LANGLADE, G. Le sujet lecteur -Lecture subjective et enseignement de la littérature. Rennes: PUR, 2004d.

Quadro europeu comum de referência para as línguas. Lisboa, ASA, 2001.

REUTER, Yves. L’Analyse du récit. Paris : Armand Colin, 2009.

ROGER, Jérome. Le ravissement du lecteur : Michaux lectomane. In - ROUXEL, A. et LANGLADE, G. Le sujet lecteur -Lecture subjective et enseignement de la littérature. Rennes: PUR, 2004e.

ROUXEL, Annie. Enseigner la lecture littéraire. Rennes: PUR, 1996. 